\title{
Seven Ways to
}

\section{Increase}

\section{Servers'Tips}

Touching, smiling, greeting, squatting, drawing happy faces,

and other simple actions are shown to increase servers' tips.

by Michael Lynn

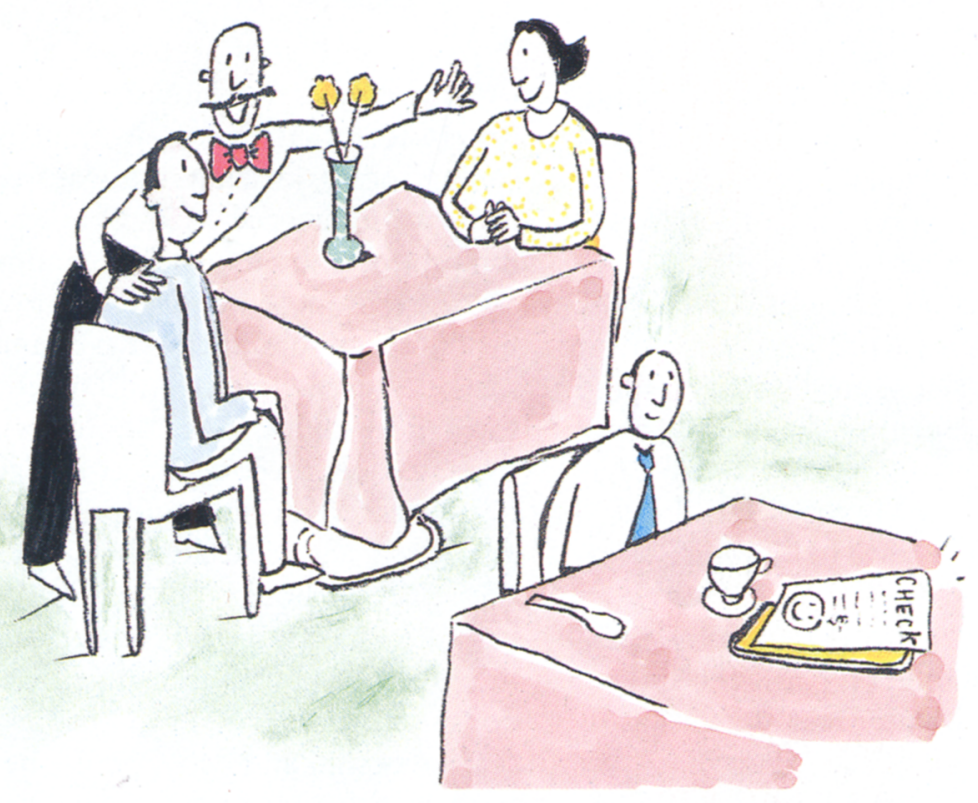

ttracting and retaining a good wait staff is a key element in attracting and retaining customers. Attentive and courteous servers can enhance customers' dining experiences, lead to positive word of mouth, and increase repeat patronage. On the other hand, uncaring or inept servers can ruin customers' dining experiences, lead to negative word of mouth, and decrease repeat patronage. Consequently, staffing wait positions is among the most important tasks restaurant managers perform.

Michael Lynn, Ph.D., is an associate professor of consumer behavior and marketing at the Cornell University School of Hotel Administration.

(C) 1996, Cornell University 
Unfortunately, many restaurants have a shortage of potential workers and a high rate of turnover. A number of articles have addressed those industry-wide problems and have recommended various solutions, such as the following: ${ }^{1}$

- recruiting new employees through referrals from current employees;

- hiring experienced applicants;

- using reliable selection tests that identify applicants most likely to be competent, long-term employees;

- communicating the company's culture, goals, policies, and expectations through the interview process and employee-orientation programs;

- empowering employees and giving them a voice in structuring the workplace;

- developing career paths for hourly employees;

- providing day care for employees' children; and

- developing stock, scholarship, and other incentive programs that reward employment longevity.

Those recommendations are all sound. However, an additional approach to dealing with recruiting and retention has been little discussed in the literature. That approach-to improve servers' tip income-is explained in this article.

\footnotetext{
${ }^{1}$ See, for example: James S. Boles, Lawrence E. Ross, and Julie T. Johnson, "Reducing Employee Turnover through the Use of Preemployment Application Demographics: An Exploratory Study," Hospitality Research Journal, Vol. 19, No. 2 (1995), pp. 19-30; Mark A. Bonn and Louis R. Forbringer, "Reducing Turnover in the Hospitality Industry: An Overview of Recruitment, Selection and Retention," International Joumal of Hospitality Management, Vol.11, No. 1 (1992), pp. 47-63; John Hogan, "Turnover and What to Do about It," Comell Hotel and Restaurant Administration Quarterly, Vol. 22, No. 4 (February 1992), pp. 40-45; and Robert H. Woods and James F. Macaulay, " $R_{x}$ for Turnover: Retention Programs That Work," Comell Hotel and Restaurant Administration Quarterly, Vol. 30, No. 1 (May 1989), pp. 79-90.
}

\section{Boosting Income}

People work primarily to make money, and dissatisfaction with income is one cause of turnover. ${ }^{2}$ Restaurant managers can attract and keep competent servers by promising and delivering them a high income. Raising wages substantially is often prohibitively costly, however. On the other hand, since servers receive the largest part of their income in the form of tips, not wages, knowledgeable managers can help their servers boost their tip percentages. Managers who know what servers can do to increase their tips can pass that knowledge on to the servers.

Psychologists have conducted a number of studies on the determinants of tipping. ${ }^{3}$ Some of the research confirms widespread industry beliefs and supports existing practices. For example, the larger the dining party, the smaller the percentage that is left; that is why many managers add automatic gratuities to the bills of larger tables. ${ }^{4}$ Research that confirms widespread beliefs is valuable, because cultural wisdom is often wrong. However, much of the research on tipping goes beyond conventional industry wisdom and suggests nonobvious, concrete ways to increase servers' tips. Seven of the more interesting research findings are reviewed in the sections that follow.

\section{Server Introduction}

Servers sometimes introduce themselves by name when greeting their

2Tony Simons and Cathy A. Enz,"Motivating Hotel Employees: Beyond the Carrot and the Stick," Cornell Hotel and Restaurant Administration Quarterly, Vol.25, No. 4 (February 1995), pp. 2027; and Boles, Ross, and Johnson, pp. 19-30.

${ }^{3}$ For a review and an extensive bibliography see: Michael Lynn, George Zinkhan, and Judy Harris, "Consumer Tipping: A Cross-Country Study," Joumal of Consumer Research, Vol. 20, No. 3 (December 1993), pp. 478-488

${ }^{4}$ Stephen Freeman, Markus R. Walker, Richard Borden, and Bibb Latane, "Diffusion of Responsibility and Restaurant Tipping: Cheaper by the Bunch," Personality and Social Psychology Bulletin, Vol. 1, No. 3 (1975), pp. 594-597. customers. Such introductions make the server seem friendly and polite and are likely to make the customer feel more empathy for the server. Both effects should increase tips. Garrity and Degelman tested that expectation in an experiment conducted at a Charlie Brown's restaurant in southern California. ${ }^{5}$

Two-person parties coming to the restaurant for Sunday brunch were randomly assigned to one of two groups. If the couple was in the "name" group, a waitress approached the table, smiled, and said: "Good morning. My name is Kim, and I'll be serving you this morning. Have you ever been to Charlie Brown's for brunch before?"

If the couple was in the "noname" group, the same approach, smile, and greeting were used, except that the waitress omitted her name.

That manipulation had a large effect on tips. The waitress received an average tip of $\$ 3.49$ (15 percent) when she did not give her name and $\$ 5.44$ (23 percent) when she did give her name. She earned almost two dollars more from each table when she introduced herself by name.

Of course, the self-introductions need to be genuine and professional. Surly or insincere introductions are likely to backfire. The words " $\mathrm{Hi}$, I'm Kim, and I'll be serving you this evening" can be irritating if said in an uncaring or automatic way.

The results of the study suggest that managers should encourage servers to introduce themselves to their customers in a sincere and professional way. The servers who do so will likely find themselves amply rewarded.

\footnotetext{
${ }^{5}$ Kimberly Garrity and Douglas Degelman, "Effect of Server Introduction on Restaurant Tipping," Joumal of Applied Social Psychology, Vol. 20, No. 2 (1990), pp. 168-172.
} 


\section{Squatting Next to the Table}

Most servers stand throughout the service encounter. However, some servers squat down next to the table when interacting with their cus-

Servers may increase their tips when they introduce themselves, squat near the table, flash smiles, touch customers, use tip trays with credit-card insignia, and write "thank you" or draw a happy face on customers' checks.

tomers. Squatting does several positive things: it increases the congruence between the server's and customers postures, facilitates eye contact by putting the server on the customers eye level, and brings the server sace closer to the customers' faces:

Research on nonverbal communication has found that postural congruence, eye contact, and close proximity are associated with rapport and liking: since consumers report that they tip friendly servers nore than they do less friendly servers, squatting down next to the table should increase a server's tips. Kirby Mynier and I tested that expectation at two restaurants in Houston. ${ }^{7}$

A Caucasian waiter at a Mexican restaurant and an Asian waitress at a Chinese restaurant flipped coins to determine whether they would squat or stand during their initial visits to tables. Otherwise, the servers tried to treat all their tables identically.

As expected, squatting significantly increased the tips of both servers. The waiter received an average tip of $\$ 5.18$ (15 percent) when he remained standing and $\$ 6.40$ (18 percent) when he squatted during his first visit to the table. The corresponding numbers for the waitress were $\$ 2.56$ (12 percent) and $\$ 3.28$ (15 percent). Overall, the servers received about a dollar more from each table at which they had squatted. That is a substantial payoff for a simple, low-cost behavior.

\footnotetext{
${ }^{6}$ Michael Argyle, Bodily Communication (New York: Methuen, 1988), pp. 88-92.

${ }^{7}$ Michael Lynn and Kirby Mynier, "Effect of Server Posture on Restaurant Tipping;" Journal of Applied Social Psychology, Vol. 23, No. 8, pp. $678-685$
}

Squatting is too informal for a fine-dining restaurant, but managers of casual-dining establishments may want to encourage their servers to squat next to their tables. There is some evidence that the management of Outback Steakhouses is already doing that. Outback servers frequently squat next to their tables and sometimes even pull out a chair to sit at the table. Of course, servers need to exercise some judgment about whether a given table will welcome such informality. However, the research suggests that those actions are generally welcome and will result in increased tips for the servers who engage in them.

\section{Smiling at Customers}

Smiling is a well-known tactic of ingratiation and social influence. Research has confirmed the cultural wisdom regarding smiling and has found that smiling people are perceived as more attractive, sincere, sociable, and competent than unsmiling people. ${ }^{8}$ The interpersonal effects of smiling suggest that servers may be able to increase their tips by smiling at their customers. Tidd and Lockard tested that possibility at a cocktail lounge in Seattle. ${ }^{9}$

Customers sitting alone in the lounge were used as subjects. The waitress randomly assigned half of them to receive a large, open-mouth smile and the other half to receive a small, closed-mouth smile. The customers receiving a small smile left an average tip of 20 cents, while those receiving a large smile left an average tip of 48 cents - an increase of 140 percent.

It is difficult to tell from those results what the effect would be for

\footnotetext{
${ }^{8}$ Harry T. Reis et al., "What Is Smiling Is Beautiful and Good," European Journal of Social Psychology, Vol. 20 (1990), pp. 259-267.

${ }^{9}$ Kathi L. Tidd and Joan S. Lockard, "Monetary Significance of the Affiliative Smile: A Case for Reciprocal Altruism," Bulletin of the Psychonomic Society, Vol. 11, No. 6 (1978), pp. 344-346.
} 
restaurant servers, because the average bill and tip sizes in restaurants are typically much larger than in cocktail lounges. However, the results do suggest that servers can increase their tips by smiling and that restaurant managers should encourage them to do so.

\section{Touching Customers}

Touching is a powerful form of interpersonal behavior that can communicate affection, appreciation, aggression, dominance, social support, and other meanings, depending on the context. In commercial settings, casually touching customers has been shown to increase the time they spend shopping in a store, the amounts they purchase, and the favorability of their store evaluations. ${ }^{10}$ Those positive effects suggest that being touched may also increase the tips that customers leave their servers. Crusco and Wetzel tested that possibility at two restaurants in Oxford, Mississippi. ${ }^{11}$

Three waitresses at two restaurants randomly assigned their customers to one of three touch conditions. Customers either were not touched, were casually touched on the shoulder once for about a second and a half, or were casually touched on the palm of the hand twice for about half a second each time. All touches occurred as the waitresses returned change to their customers at the end of the meal. Eye contact was avoided during the process.

The effects of the touch manipulation were significant. Customers left an average tip of 12 percent when not touched, 14 percent when

\footnotetext{
${ }^{10} \mathrm{Jacob}$ Hornik, "Tactile Stimulation and Consumer Response," Journal of Consumer Research, Vol. 19 (December 1992), pp. 449-458. ${ }^{11}$ April H. Crusco and Christopher G. Wetzel, "The Midas Touch:The Effects of Interpersonal Touch on Restaurant Tipping," Personality and Social Psychology Bulletin, Vol. 10, No. 4 (December 1984), pp. 512-517.
}

touched once on the shoulder, and 17 percent when touched twice on the palm. Subsequent research by other investigators has demonstrated that casually touching customers increases the tips of both male and female servers and that the effect is strongest when servers touch the female members of dining parties. ${ }^{12}$

The results of those studies suggest that managers should encourage servers to briefly and casually touch their customers. Many managers will feel uncomfortable with that recommendation; they will fear that customers would object to being touched. However, researchers have found that subjects whose behavior has been influenced by touches are often unaware that they have been touched. ${ }^{13}$ Servers'

touches need not be obtrusive to be effective.

Moreover, the benefits of touching accrue to more than just the server. Customers who are touched by servers evaluate the restaurant more favorably than those who are not touched. ${ }^{14}$ Managers may find that the benefits of touching customers more than outweigh the slight risks.

\section{Credit-Card Insignia on Tip Trays}

Restaurants often post signs informing customers that credit cards are accepted. Those signs, and other displays of credit-card insignia, can be seen on restaurant doors, windows, counters, menus, table tents, tip trays, and cash registers.

Research has found that simply seeing those insignia increases consumers' willingness to spend

\footnotetext{
${ }^{12}$ Hornik, pp. 449-458; and Renee Stephen and Richard L. Zweigenhaft, "The Effect on Tipping of a Waitress Touching Male and Female Customers," Journal of Social Psychology, Vol. 126, No. 1 (1986), pp. 141-142.

${ }^{13}$ Jeffrey D. Fisher, Marvin Rytting, and Richard Heslin, "Hands Touching Hands: Affective and Evaluative Effects of Interpersonal Touch," Sociometry, Vol. 39, No. 3 (1976), pp. 416-421.

${ }^{14}$ Hornik, pp. 449-458; see also Fisher, Rytting, and Heslin, pp. 416-421.
}

money. ${ }^{15}$ That effect may be due to the fact that credit-card insignia are so often present when consumers buy things that the insignia have become conditioned stimuli that elicit spending. Alternatively, creditcard insignia may remind consumers of the availability of credit and thereby increase their perception of their own spending power, even when they intend to pay with cash.

Regardless of the explanation, the effect suggests that servers may receive larger tips when credit-card insignia are present at the table. McCall and Belmont tested that hypothesis at two establishments-a family restaurant and a café-in upstate New York. ${ }^{16}$

The presence and absence of credit-card insignia were manipulated using tip trays. Trays with credit-card emblems on them and trays without such emblems were randomly mixed, and servers took trays as needed from the top of the stack. At both establishments customers tipped significantly more when the bill was presented on a tip tray with a credit-card emblem. Tips increased from 16 percent to 20 percent of pretax bills at the restaurant and from 18 percent to 22 percent at the café. The effect was not due to an increased use of credit cards to pay the bill. In fact, all the café's customers paid in cash. Simply seeing the insignia on the tip trays apparently caused customers to tip an additional 4 percent of their bill.

In light of those results, managers may want to replace plain tip trays with trays that contain creditcard emblems. Those tip trays, which can be obtained at little or

\footnotetext{
${ }^{15}$ Richard A. Feinberg, "Credit Cards as Spending-Facilitating Stimuli: A Conditioning Interpretation," Journal of Consumer Research, Vol. 13 (1986), pp. 348-356.

${ }^{16}$ Michael McCall and Heather J. Belmont, "Credit Card Insignia and Tipping: Evidence for an Associative Link" (unpublished paper, Ithaca College, 1995).
} 


\section{Conduct Your Own Tests}

Research has demonstrated that servers can increase their tips by performing certain actions such as squatting down next to tables or writing "Thank you" on checks. However, each of the studies demonstrating those effects typically involved only one or two restaurants, and managers may wonder whether they can expect similar results. Although I believe the results will generalize to most restaurants, I encourage and challenge managers to perform their own tests. Managers may also test other actions that they expect to increase tips (e.g., calling customers by their names or giving customers after-dinner mints).

To rigorously test an action, it is necessary to have servers randomly assign their customers to receive different treatments. If the sample is large enough, random assignment ensures that the groups receiving different treatments are comparable on all other relevant dimensions and that any difference in tips is due to the treatments.

Random assignment can be accomplished in several ways. If only two treatments are being studied, the simplest way is to flip a coin. Assign the table to one treatment group if the coin's head comes up and to the other if the tail comes up. Another way is to get an index card for each table in the study, write one treatment name on half the cards and the other treatment name on the other half, shuffle the cards thoroughly, and pull a card from the shuffled deck to determine what treatment a table will receive (do not replace that card in the deck).

Although slightly more complicated than flipping a coin, the second procedure has two advantages. First, it ensures that there are equal numbers of tables in each treatment group when the deck of index cards is depleted. Second, the procedure can easily be modified to randomly assign tables to three or more treatments by simply writing the names of each treatment on an equal number of index cards before shuffling them.

Another issue is the effect of server expectancy. Knowing what treatment their customers are assigned to receive might subtly influence servers' behavior toward the customers. For example, a waiter who believes that a particular treatment will increase tips may be more attentive and friendly to the customers assigned to that treatment simply because he is already expecting bigger tips from them. That could bias the results. It would not be clear whether any increase in tips was due to the experimental treatment alone or to other differences in the server's behavior.

Server-expectancy effects can be minimized by limiting server interactions with the customers after they have been assigned to treatments. One way to do that is to conduct the test during periods of buffet service, as Garrity and Degelman did in their study. Another way is to assign customers to treatments just before delivering the check or change (for those treatments where doing so is sensible). That is what Crusco and Wetzel, McCall and Belmont, and Rind and Bordia did. Of course, server-expectancy effects can be avoided altogether if the servers do not expect the treatments to affect tips. Thus managers may want to use servers who do not think the experimental treatment will affect their tips. That is what Mynier and I did in our study.

Participating servers need to include in the study all the tables meeting predetermined qualifications and record each table's treatment, bill size, and tip amount. Tables with separate checks should be treated as one-check tables or dropped from the study. At least 50 tables should be included in each treatment.

Once the data have been collected, managers can compare the average percentage and dollar tip amounts from each treatment. Ideally, a t-test or F-test would be used to see if any observed differences are within the range attributable to chance. Those statistical tests can be performed with a spreadsheet program like Excel. If such software is not available, the manager can look in any standard statistics textbook to find out how to conduct the tests by hand.

There is no good substitute for conducting the statistical tests, but for managers who do not have the resources to do so, a general rule of thumb is that the larger the differences and the larger the size of the sample, the less likely that the results are due to chance. If there is any question about whether an effect and a sample size are large enough to rule out chance, managers can always repeat the test to see whether its results are reliable.-M.L. no cost from credit-card companies, will increase the incomes of servers who use them.

\section{Writing "Thank You" on Checks}

Servers sometimes write "Thank you" and sign their name on the backs of checks before they deliver them to their customers. Those expressions of gratitude may increase the perceived friendliness of the server, which would increase tips. Expressions of server gratitude may also make customers feel obligated to earn that gratitude by leaving larger tips. Whatever the mechanism involved, expressions of gratitude seem likely to increase tips. Rind and Bordia tested that expectation at an upscale restaurant in Philadel- phia. ${ }^{17}$ In their study, a waitress randomly assigned her lunch customers to one of three groups. On the back of the check she either wrote nothing, wrote "Thank you," or wrote "Thank you" and signed her name.

As expected, the expression of gratitude significantly affected the size of her tips. She received an average tip of 16 percent when she wrote nothing on the back of the check and 18 percent when she wrote "Thank you." Adding her signature to the thanks produced the same level of tips as the thanks alone.

\footnotetext{
${ }^{17}$ Bruce Rind and Prashant Bordia,"Effect of Server's 'Thank You' and Personalization on Restaurant Tipping," Journal of Applied Social Psychology, Vol. 25, No. 9 (1995), pp. 745-757.
}

Since there is little downside to an expression of gratitude, managers should encourage or even require servers to write "Thank you," or a comparable message, on the backs of their checks. Doing so will increase tips.

\section{Drawing a Happy Face on Checks}

Some waitresses draw a "happy face" on the backs of checks. Those drawings are likely to have several effects. They may personalize the server to customers and thereby increase the empathy for the server. They may communicate to customers that the server is happy to have served them, which would ingratiate the server to the customers. And they may simply make customers smile themselves and thereby improve their mood. All those 
potential effects suggest that drawing a happy face on the backs of checks will increase tips. Rind and Bordia tested that possibility in a study conducted at the same upscale Philadelphia restaurant that was the setting for their "thank you" research. ${ }^{18}$

A waiter and a waitress at the restaurant gave half their lunch customers a check on which the server had drawn a happy face and the other half a check without the drawing. The determination of what tables got what type of check occurred at the end of the meal, when most of the service had already been rendered. When the server was ready to deliver the check, the server randomly determined the group the table was assigned to and either drew a happy face on the check or did not.

The manipulation significantly affected the waitress's tips, but not the waiter's. The waitress received an average tip of 28 percent when she drew nothing on the check and 33 percent when she drew a happy face. Drawing a happy face increased the waitress's tips by 18 percent.

The waiter experienced no comparable effect and may actually have diminished his tips. He received an average tip of 21 percent when he drew nothing on the check and only. 18 percent when he drew a happy face. Although the decrease in tip size was not statistically significant, it suggests that drawing a happy face may actually backfire for waiters. Perhaps such drawings are considered too emotional or feminine to be acceptable coming from a man.

The results of the study suggest that restaurant managers can improve their waitresses' tips by encouraging them to draw happy faces on their checks. Of course, drawing such faces may be too informal for fine-dining establishments.

\footnotetext{
${ }^{18}$ Bruce Rind and Prashant Bordia, "Effect on Restaurant Tipping of Male and Female Servers Drawing a Happy, Smiling Face on the Backs of Customers' Checks," in press.
}

It is possible that male servers could benefit from drawing more masculine pictures on their checks and that a more formal drawing would be appropriate for a fine-dining restaurant. For example, servers at an upscale seafood restaurant could make a simple line drawing of a lobster claw. Such drawings should serve as well as happy faces to personalize servers and therefore increase tips.

\section{Tips for Earning Tips}

Psychological research on tipping has found that servers earn larger tips when they introduce themselves by name, squat down next to the table, flash large smiles, touch their customers, use tip trays with credit-card insignia, write "thank you" on the backs of checks, and draw a happy face on the backs of checks. Most of those simple actions increased tips by 20 percent or more (see Exhibit 1). Restaurant managers can substantially improve their servers' incomes by encouraging them to take those actions, and they can use the research results reviewed here to convince servers that doing so will be to their benefit.

To get a clear picture of the income gains possible, assume that a server waits on 20 people per shift who spend $\$ 15$ and leave a tip of $\$ 2.25$ (15 percent). The server would earn $\$ 45$ in tips in a shift, or $\$ 225$ in tips in a five-shift workweek.

If the server squats down next to all of his or her tables and increases the tips by 20 percent, she or he would earn $\$ 54$ in tips in a shift, or $\$ 270$ in tips in a workweek. In other words, the server would bring home almost $\$ 200$ extra a month simply by squatting down next to tables. Similar gains would be expected if the server took any of the other simple actions discussed above.

The psychological research demonstrates that servers can substantially increase their income by performing any one of several specific actions. However, the effects of the actions may not be additive. More research is needed to be certain, but it seems likely that as tip size goes up, so does resistance to further increases. That is, combining actions that separately increase tips will probably not produce an even larger effect. Thus managers can maximize their servers' incomes without encouraging them to do all the things discussed.

Not all of the tip-enhancing actions are appropriate for every restaurant or server. Managers can pick the actions that seem most appropriate for their restaurants and encourage their servers to perform one or two acts from that shorter list of actions. The actions are innocuous, and every manager should be able to find several things to recommend to the wait staff. Moreover, the actions are varied enough that every server should be able to find something he or she would be comfortable doing. CQ 